\title{
Potent activation of FGF-2 IRES-dependent mechanism of translation during brain development
}

\author{
SYLVIE AUDIGIER, ${ }^{1,2,5}$ JANIQUE GUIRAMAND, ${ }^{3,5}$ LEONEL PRADO-LOURENCO,${ }^{1,2,4}$ CAROLINE CONTE, ${ }^{1,2}$ \\ IRMA GABRIELA GONZALEZ-HERRERA, ${ }^{1,2}$ CATHERINE COHEN-SOLAL, ${ }^{3}$ MAX RÉCASENS, ${ }^{3}$ \\ and ANNE-CATHERINE PRATS ${ }^{1,2}$ \\ ${ }^{1}$ Institut National de la Santé et de la Recherche Médicale (INSERM), U858, Toulouse, France \\ ${ }^{2}$ Université Toulouse III Paul Sabatier, Institut de Médecine Moléculaire de Rangueil, IFR31, Toulouse, France \\ ${ }^{3}$ Max Mouserron Institute on Biomolecules (IBMM)-UMR5247-CNRS-Université Montpellier 1-Université Montpellier 2, \\ 34095 Montpellier Cedex 5, France \\ ${ }^{4}$ MilleGen, Prologue Biotech, BP28262, 31682 Labège, France
}

\begin{abstract}
Fibroblast growth factor-2 (FGF-2) plays a fundamental role in brain functions. This role may be partly achieved through the control of its expression at the translational level via an internal ribosome entry site (IRES)-dependent mechanism. Transgenic mice expressing a bicistronic mRNA allowed us to study in vivo and ex vivo where this translational mechanism operates. Along brain development, we identified a stringent spatiotemporal regulation of FGF-2 IRES activity showing a peak at post-natal day 7 in most brain regions, which is concomitant with neuronal maturation. At adult age, this activity remained relatively high in forebrain regions. By the enrichment of this activity in forebrain synaptoneurosomes and by the use of primary cultures of cortical neurons or cocultures with astrocytes, we showed that this activity is indeed localized in neurons, is dependent on their maturation, and correlates with endogenous FGF-2 protein expression. In addition, this activity was regulated by astrocyte factors, including FGF-2, and spontaneous electrical activity. Thus, neuronal IRES-driven translation of the FGF-2 mRNA may be involved in synapse formation and maturation.
\end{abstract}

Keywords: FGF-2; protein synthesis; IRES; development; brain; neuron

\section{INTRODUCTION}

During their whole life span, cells from the central nervous system (CNS) are subjected to plastic changes, which depend on the action of growth factors like fibroblast growth factor-2 (FGF-2). Indeed, FGF-2 plays multiple roles both during CNS development and in the adult, such as in proliferation and differentiation of neural precursor cells (neurons or glia), neuritogenesis, synapse formation, neuroprotection, cognitive processes, post-lesional repair, and blood-brain barrier formation (Vaccarino et al. 1999; Gremo and Presta 2000; Reuss and von Bohlen und Halbach 2003). This prominent role is illustrated by the FGF-2 knock-out mice that coped with severe neuronal and glial

\footnotetext{
${ }^{5}$ These authors contributed equally to this work.

Reprint requests to: Sylvie Audigier, Institut National de la Santé et de la Recherche Médicale (INSERM), U858, I2MR, Equipe 11, Bâtiment L3, 1, Avenue Jean Poulhès, BP 84225, 31432 Toulouse Cedex 4, France; e-mail; sylvie.audigier@inserm.fr; fax: 33561322141.

Article published online ahead of print. Article and publication date are at http://www.rnajournal.org/cgi/doi/10.1261/rna.790608.
}

deficits particularly in the cerebral cortex (Dono et al. 1998; Ortega et al. 1998; Vaccarino et al. 1999; Korada et al. 2002).

The wide range of FGF-2 cerebral functions may be partly achieved by the control of its expression at the translational level. For instance, the FGF-2 mRNA contains multiple translational alternative initiation sites leading to the synthesis of five isoforms (Florkiewicz and Sommer 1989; Prats et al. 1989; Arnaud et al. 1999; Touriol et al. 2003). In addition, this mRNA exhibits an internal ribosome entry site (IRES) in its 5' untranslated region (UTR) (Vagner et al. 1995). Consequently, it can be alternately translated either by the classical cap-dependent mechanism or by the unusual IRES-dependent mechanism. Such a peculiar mechanism of translation was first discovered for picornavirus mRNAs, which lack a cap in their 5' UTR (Pelletier and Sonenberg 1988), and subsequently characterized in eukaryotic mRNAs, first in Bip mRNA (Macejak and Sarnow 1991) and then in a growing number of mRNAs (van der Velden and Thomas 1999; Bonnal et al. 2003; Stoneley and Willis 2004; Komar and Hatzoglou 2005; Baird et al. 2006).

The cellular events driving IRES-dependent translation are, however, still far from being understood. IRESs may 
allow translation in a proper time and space when capdependent translation is impaired. Accordingly, cellular stress or mitosis, which leads to inhibition of total protein synthesis through the blockade of cap-dependent translation, favors IRES-dependent translation (Bonnal et al. 2003; Qin and Sarnow 2004; Sherrill et al. 2004; Holcik and Sonenberg 2005). Using transgenic mice expressing a bicistronic mRNA, Creancier et al. (2000) found a heterogeneous distribution of this FGF-2 IRES activity throughout adult tissues, and notably a high IRES activity in the brain. In the adult, FGF-2 is localized in neurons as well as in astrocytes and implicated in brain plasticity (Ishiyama et al. 1991; Abe et al. 1992), a phenomenon that recapitulates some developmental events. Accordingly, we decided to determine whether FGF-2 IRES-dependent translation could be part of these processes, by studying where and when this translational mechanism operates in the CNS.

In this article, we reveal a specific and stringent spatiotemporal regulation of FGF-2 IRES activity throughout brain regions. At the cellular level, a strong IRES activity was detected in a neuronal compartment, the synaptoneurosomes. Studies carried out on primary cultures or cocultures of cortical neurons and astrocytes confirmed the neuronal localization of this activity and revealed its dependency on neuronal maturation and its regulation by astrocyte factors as well as by electrical activity.

\section{RESULTS}

\section{Bicistronic transgenic mouse model}

The bicistronic transgenic mouse represents an appropriate model to study the regulation of FGF-2 IRES-dependent translation in an in vivo context. The bicistronic construct expressed under the control of the cytomegalovirus promoter contains an upstream cistron coding for Renilla luciferase (RLuc), which is separated from a downstream cistron coding for Firefly luciferase (FLuc) by the sequence of the FGF-2 IRES (Fig. 1A; Creancier et al. 2000). Enzymatic activity of RLuc reflects the levels of cap-dependent translation and is directly correlated with the number of bicistronic trancripts. On the other hand, enzymatic activity of FLuc corresponds to the levels of FGF-2 IRESdependent translation. Consequently, the ratio of FLuc to RLuc activity reflects FGF-2 IRES activity, independently of the transgene expression level.

\section{Regional distribution of FGF-2 IRES activity in the adult mouse brain}

In the adult (P42), FGF-2 IRES activity measured in various brain regions of bicistronic transgenic mice was heterogeneous, being particularly high (ratio above 10) in neocortex (CTX) and striatum (STR) (Fig. 1B; Table 1). A lower but still consistent activity was observed in the hippocampus
A

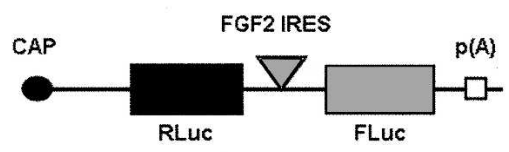

B

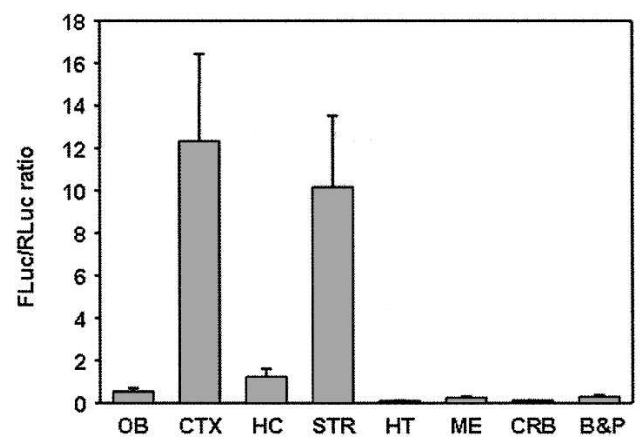

c

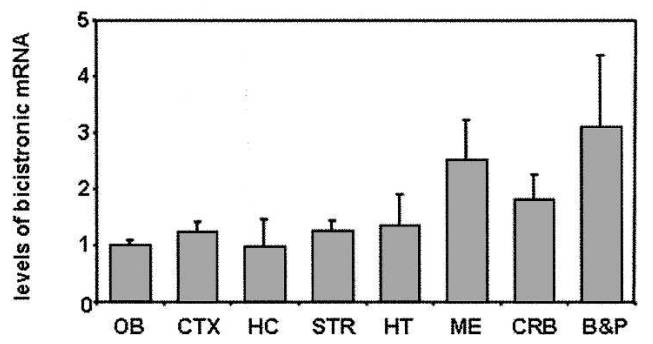

FIGURE 1. Brain distribution of FGF-2 IRES activity in the adult transgenic mouse. (A) Schematic representation of the bicistronic luciferase mRNA construct containing the FGF-2 IRES. The plasmid (pCRFL) used to generate RFL12 transgenic mice is described in Creancier et al. (2000). Expression of the transgene is under the control of the CMV promoter. (B) Regional distribution of FGF-2 IRES activity. Homogenates were prepared from different brain areas of adult RFL12 transgenic mice. (OB) olfactory bulb, (CTX) neocortex, (HC) hippocampus, (STR) striatum, (HT) hypothalamus, (ME) mesencephalon, (CRB) cerebellum, (B\&P) bulb and pons). Renilla (RLuc) and Firefly (FLuc) luciferase activities were measured as described in Materials and Methods. FGF-2 IRES activity is calculated by the ratio FLuc/RLuc. Values represent the means \pm SEM of determinations obtained from nine mice. (C) Regional distribution of the bicistronic mRNA. RNAs were extracted from the same brain areas and reverse transcribed. Levels of bicistronic mRNAs were measured by real time RT-PCR as described in Materials and Methods. Expression levels in $\mathrm{OB}(\mathrm{Ct}$ values $=30.4 \pm 0.6)$ were set to 1 as the calibrator and the values are given as mean ratios \pm SEM of bicistronic mRNAs in one brain area relative to those measured in OB. These values were obtained in four separate experiments.

(HC) and olfactory bulb (OB) (ratio around 1 and 0.5 , respectively). In other cerebral regions, hypothalamus (HT), cerebellum (CRB), mesencephalon (ME), and bulb and pons $(\mathrm{B} \& \mathrm{P})$, ratios of activity ranged from 0.08 to 0.28 , but these lower values were still higher than those previously measured in other organs by Creancier et al. (2000). Similar values were obtained in the brain regions of heterozygote mice and of another strain of bicistronic transgenic mice, RFLD (data not shown). Expression levels of bicistronic mRNAs measured by quantitative RT-PCR were rather 


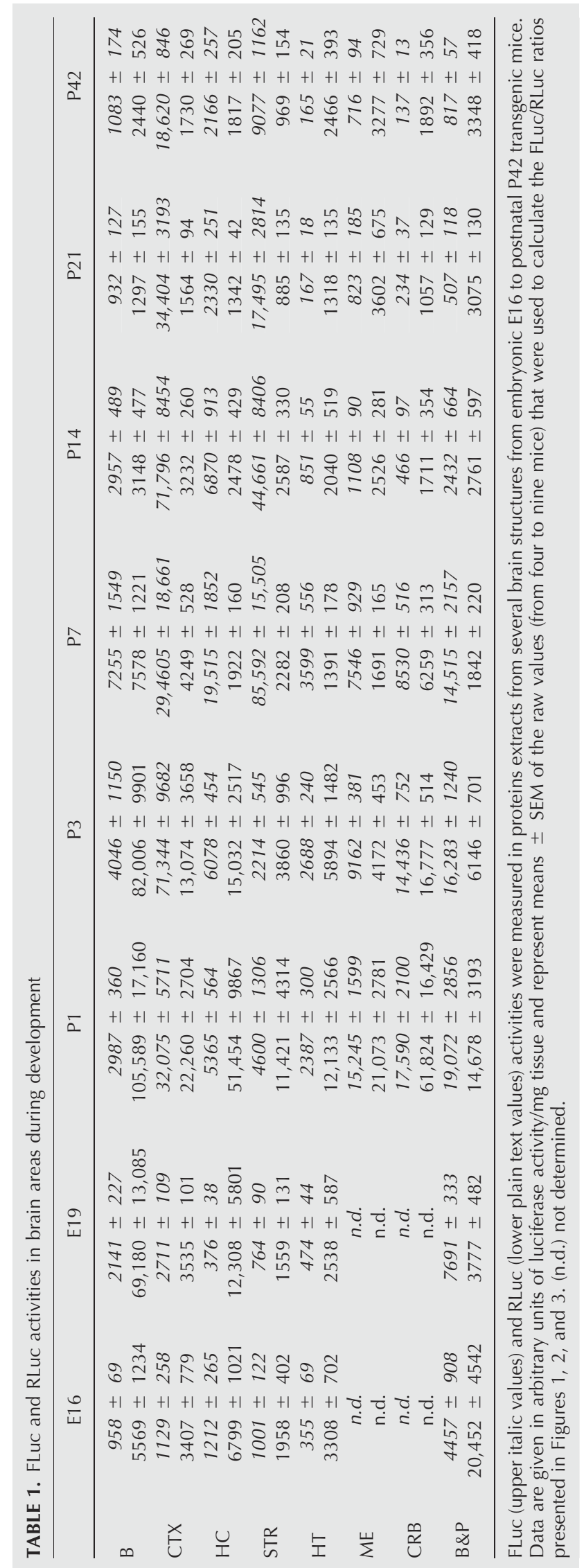


homogeneous throughout all brain areas, except in ME and $\mathrm{B} \& \mathrm{P}$ (Fig. 1C). Interestingly, the higher mRNA expression in these two brain areas was correlated with a higher RLuc activity (Table 1).

Altogether, these findings reveal that the different levels of FLuc activity observed in various brain areas are not linked to variations in bicistronic mRNA transcription, and thus probably result from a differential activation of the FGF-2 IRES-dependent translation.

\section{Developmental regulation of FGF-2 IRES activity in various brain structures}

As FGF-2 is implicated in brain development, we measured FGF-2 IRES activities from embryo (E16) to adulthood (P42) in different brain structures (Fig. 2). Before E16, the IRES activity determined in body and head of the embryo at E11 was extremely low, i.e., $0.060 \pm 0.001$ (FLuc/mg tissue $=1228 \pm 219 ; \mathrm{RLuc} / \mathrm{mg}$ tissue $=19,968 \pm 4196)$ and $0.087 \pm 0.003(\mathrm{FLuc} / \mathrm{mg}$ tissue $=303 \pm 17 ; \mathrm{RLuc} / \mathrm{mg}$ tissue $=$ $3481 \pm 116)$, respectively.

In all brain areas except OB, a peak of high FGF-2 IRES activity was observed at $\mathrm{P} 7$, although with different patterns from one area to another (Fig. 2; Table 1). In the OB, the IRES activity after $\mathrm{P} 7$ reached a plateau and decreased only slightly in the adult. In CTX, STR, and HC, a sharp increase was observed between P3 and P7, followed by a decrease between $\mathrm{P} 7$ and P14, and finally a plateau. In contrast to these regions, the IRES activity in CRB, HT, ME, and B\&P decreased after P7 and rapidly dropped to the low values observed in the adult. The B\&P was the only structure, which showed a substantial IRES activity (above 2) earlier, in the E19 embryo. It should be mentioned that a peak of RLuc activity took place at P1 in all brain areas, the following decrease being concomitant with the increase in FLuc activity, which peaked at P7.

Taken together, this developmental study reveals the existence of a stringent spatiotemporal regulation of FGF-2 IRES activity from embryonic life to adulthood.

\section{FGF-2 IRES activity throughout cortical areas}

As illustrated in Table 2, we analyzed more precisely the distribution of IRES activity within the highly structured neocortex and found marked differences between each subcortical area. The highest IRES activities were detected both in frontal and temporal CTX, two regions known to be involved in long-term memory storage. About 3 times lower IRES activities were observed in parietal and cingular CTX, and the lowest activity was found in the occipital visual region. The heterogeneity of IRES activity within the CTX strongly supports the participation of this mechanism of translation in specific brain functions of FGF-2.

\section{Specificity of the FGF-2 IRES activity in brain regions at P7}

As FGF-2 IRES activities were very high at P7 in most brain regions, we investigated whether this peak of activity could be observed in other tissues. In kidney and heart, FLuc/ RLuc ratios were very low $(0.020 \pm 0.001$ and $0.011 \pm$ 0.001 , respectively) at P7 and similar to those found in the adult (Creancier et al. 2000). Accordingly, the high FGF-2 IRES activity and its peak at $\mathrm{P} 7$ are specific to the cerebral tissue, and its temporal variation suggests a link with brainspecific developmental processes.

The specificity of FGF-2 IRES activity at P7 was further addressed by the comparison with other IRESs in similar bicistronic transgenic mice (Fig. 3). IRES activities of vascular endothelial growth factor (VEGF), of the proto-oncogene c-myc, and of the encephalomyocarditis virus (EMCV) were much lower than that of FGF-2 in all brain areas at P7: FLuc/RLuc ratios ranged from 0.2 to 0.8 for c-myc and EMCV IRESs, and those for VEGF were even lower (around $0.06)$. In addition, only small variations were detected from one brain area to another. All these data emphasize the specific regulation pattern of the FGF-2 IRES element.

\section{Integrity of the bicistronic mRNA}

We then verified that the specific increase in IRES activity observed at P7 did not result from cap-dependent translation of monocistronic Fluc mRNAs (Han and Zhang 2002; Kozak 2003; Van Eden et al. 2004; Liu et al. 2005; Wang et al. 2005). This possibility was checked by the sensitive quantitative RT-PCR method using RLuc- and FLuc-specific probes for the detection of bicistronic and putative additional monocistronic transcripts (TeshimaKondo et al. 2004; Holcik et al. 2005). In RNAs extracted from both P7 forebrain and adult brain of transgenic mice, the equimolar concentration of both cistron transcripts (Fig. 4) showed the integrity of the bicistronic mRNA, thereby confirming that the stringent regulation observed during brain development results from the specific activation of the IRES-dependent mechanism of translation (Creancier et al. 2000; Teshima-Kondo et al. 2004).

\section{Neuronal localization of FGF-2 IRES activity}

As FGF-2 mRNA and proteins have been localized in both neuronal and glial cells (Gomez-Pinilla et al. 1994), we investigated whether FGF-2 IRES activity was present in both cell types. First, we measured the IRES activity in a fraction enriched in synaptoneurosomes from P6-P7 transgenic mouse forebrain. The quality of the enrichment was revealed by the concomitant enhancement in a synaptic terminal marker (post-synaptic density PSD95 protein) content and impoverishement in a glial marker (glial fibrillary acidic protein [GFAP]) content within the preparation (Fig. 5A). Interestingly, the FLuc/RLuc ratio reached 38 

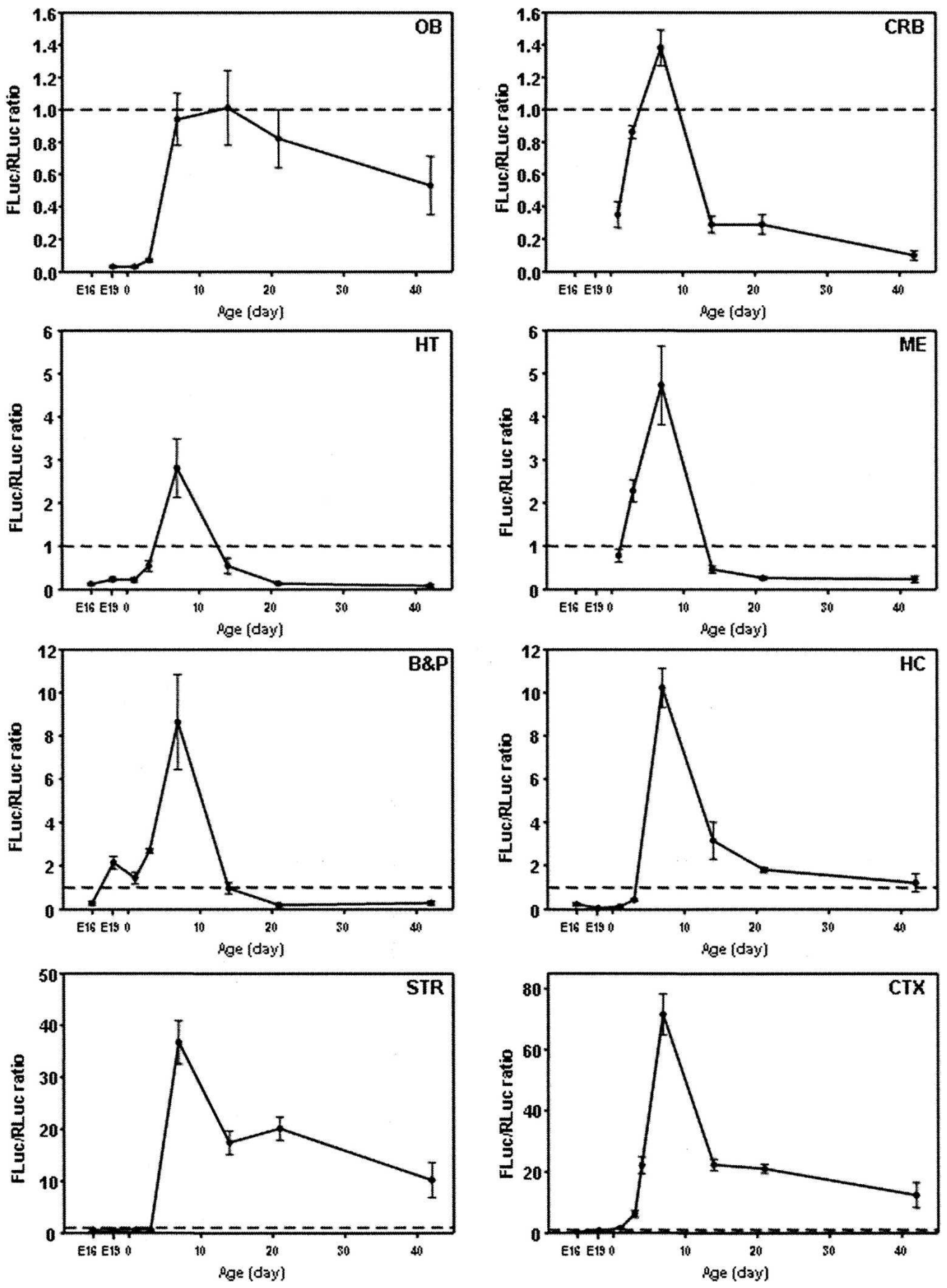

FIGURE 2. Spatiotemporal regulation of FGF-2 IRES activity during embryonic and postnatal development of transgenic mice. Homogenates were prepared from different brain areas of E16 to P42 RFL12 transgenic mice. Luciferase activities were measured as described in Materials and Methods. FGF-2 IRES activity is given as the FLuc/RLuc ratio and the dotted line corresponds to a ratio of 1 . Values represent the means \pm SEM of determinations obtained from four to nine mice.

in the synaptoneurosome fraction, i.e., twice the ratio measured before enrichment (Fig. 5B).

We then measured FGF-2 IRES activity in primary cultures of cortical neurons or astrocytes from transgenic mice. It is noteworthy that FGF-2 IRES activities in freshly dissociated cortical cells were similar to those measured in whole intact CTX at the same developmental stage, i.e., very low at E16 (ratio of 0.03 ) and much higher at P3-5 (ratio above 10) (Table 3). After $10 \mathrm{~d}$ in vitro (DIV), FLuc/ RLuc ratio was above 1 in neurons and very low (0.05) in 
TABLE 2. Heterogeneity of FGF-2 IRES activity in the mouse neocortex

\begin{tabular}{lc}
\hline Cortical area & $\begin{array}{c}\text { FGF-2 IRES activity } \\
(\% \text { of whole neocortex })\end{array}$ \\
\hline Frontal & $160 \pm 24$ \\
Parietal & $59 \pm 5$ \\
Temporal & $129 \pm 12$ \\
Occipital & $31 \pm 5$ \\
Cingular & $48 \pm 19$ \\
\hline
\end{tabular}

Neocortex from P7 RFL12 mice was subdissected and FGF-2 IRES activity measured, as described in Materials and Methods. Data are expressed as percentages of the values obtained in the whole CTX of transgenic mice. Values represent the means \pm SEM of measurements in four mice.

astrocytes, corresponding to a 49-fold increase in activity for neurons and a 289-fold decrease for astrocytes.

Finally we visualized in situ the cellular localization of the Firefly reporter protein by immunocytochemistry in 10 DIV neuronal cultures, where less than $10 \%$ astrocytes can be observed. Neurons identified by specific markers, $\beta$ tubulin or microtubule associated protein 2 (MAP2) (red labeling), displayed a strong FLuc green immunofluorescent signal (Fig. 5C, i,ii), which was present in most neurons (Fig. 6D). On the other hand, FLuc signal was never detected in astrocytes, easily identified by the GFAP immunoreactivity (red labeling) (Fig. 5C, iii). A typical astrocyte surrounded by neuronal projections and devoid of FLuc can also be observed in Figure 5C, ii.

Taken together, these data demonstrate that the FGF-2 IRES-dependent translation takes place in neurons.

\section{Regulation of FGF-2 IRES activity in cortical cultures of neurons and cocultures of neurons/astrocytes}

The increase in IRES activity during the first post-natal week coincides with a period of intense astrocyte proliferation, and these cells are known to strongly influence neuronal development both in vivo and in vitro (Lieth et al. 1989; Hertz 1991; Goritz et al. 2002; Lippman and Dunaevsky 2005). We therefore examined the regulation of IRES activity both in cultures of neurons and in cocultures of neurons/astrocytes.

Anti- $\beta$-tubulin immunocytochemistry clearly revealed that the cocultures displayed both at 3 DIV and 10 DIV a large increase in neuritic processes when compared to the neuronal cultures (Fig. 6A). From 3 to 19 DIV, we observed in these cocultures a stringent regulation of IRES activity (Fig. 6B), with a remarkable peak at 10 DIV. Interestingly, this activity at 3 DIV was already 10 times higher $(0.3)$ than in the E16 dissociated cells (0.03), increased at each step until 10 DIV, where it reached the highest value (FLuc/ RLuc ratio around 10), and subsequently dropped. Although neuronal cultures presented similar kinetics of IRES activity with the peak at 10 DIV, changes of IRES activity occurred later, after 5 DIV, and levels of activity were much smaller at any developmental stage (Fig. 6B). The transient peak of IRES activity resulted from opposite variations of FLuc and RLuc activities in the cocultures (Fig. 6C) and in neuronal cultures (data not shown). The highest RLuc activity was observed at 3 DIV while the highest FLuc activity was detected at 10 DIV, corresponding from 3 DIV to 10 DIV to a sevenfold decrease in RLuc activity and a

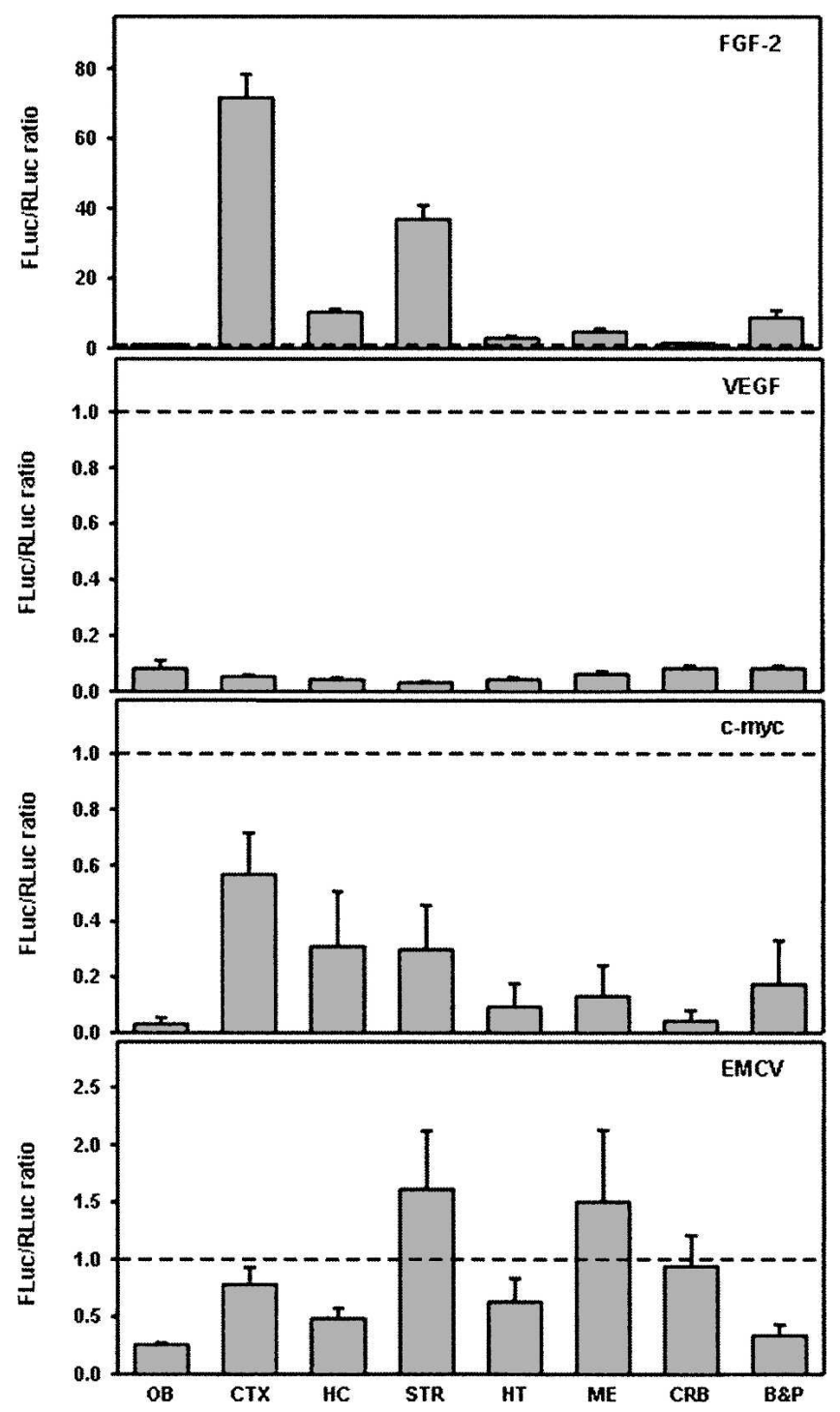

FIGURE 3. Brain distribution of different IRES activities in P7 transgenic mice. Transgenic mice expressing bicistronic constructs bearing IRES from either eukaryotic (FGF-2, VEGF, c-myc, and VEGF) or picornaviral (EMCV) mRNA are described in Materials and Methods. Homogenates were prepared at postnatal day P7 from various brain areas of the different transgenic mice. Luciferase activities were measured as described in Materials and Methods. FGF-2 IRES activity is given as the FLuc/RLuc ratio, and the dotted line corresponds to a ratio of 1 . Values represent the means \pm SEM of determinations obtained from four to nine mice. 


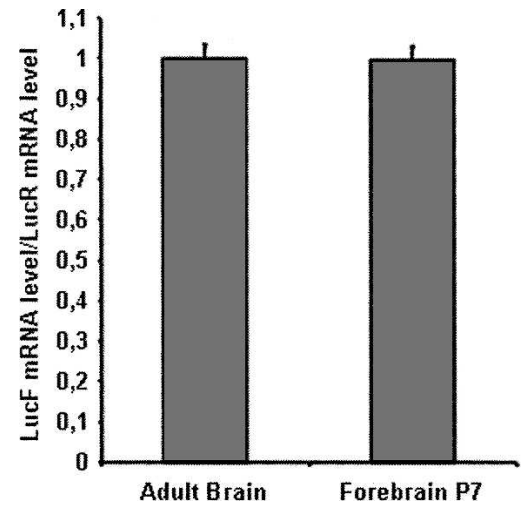

FIGURE 4. Bicistronic mRNA integrity. RNAs were prepared from P7 forebrains and adult brains of RFL12 transgenic mice and reverse transcribed as described in Materials and Methods. Levels of reporter RLuc and FLuc mRNAs were measured by a real-time RT-PCR as described in Materials and Methods. The Ct values obtained with RLuc probes were $28.56 \pm 0.1$ in the adult and $29.51 \pm 0.06$ at P7 whereas the $\mathrm{Ct}$ values obtained with Fluc probes were $28.78 \pm 0.1$ in the adult and $29.49 \pm 0.05$ at P7. Results are expressed as the mean ratio of FLuc relative mRNA level/RLuc relative mRNA level \pm SEM resulting from triplicate determinations obtained in two mice.

fourfold increase in FLuc activity. To determine whether changes of bicistronic mRNA expression might be involved in these opposite variations, levels of these mRNAs were measured by real time RT-PCR at these two representative developmental stages of cell cultures. As the $\mathrm{Ct}$ values obtained at $3 \mathrm{DIV}(\mathrm{Ct}=33.7 \pm 1.8, n=6)$ and $10 \mathrm{DIV}$ $(\mathrm{Ct}=33.4 \pm 0.5, n=6)$ were not significantly different, it strongly indicated that the variations in luciferase activities do not result from changes of bicistronic mRNA expression, but rather correspond to a switch in translational mechanism. In addition, the change in FLuc activity was reflected by a similar variation in the immunofluorescence FLuc signal intensity detected in these neuronal cultures (Fig. 6D).

In order to address the physiological relevance of these findings, we analyzed the endogenous expression of the FGF-2 protein at the same developmental stages in neuronal cultures. While absent at 3 DIV, FGF-2 protein (red labeling) was detected into neurons at 10 DIV, mostly as a cytoplasmic punctuated signal (Fig. 6E).

In these ex vivo studies, we characterized a sharp regulation of FGF-2 IRES-dependent translation in neurons, which correlates with the temporal expression of endogenous FGF-2 and is strongly potentiated by astrocytes.

\section{Regulation of FGF-2 IRES activity by astrocyte conditioned medium and growth factors}

An important role of astrocytes is to actively participate in neuronal maturation, partly through diffusible signals. Interestingly, addition of astrocyte-conditioned medium (ACM) to cortical neurons induced a strong increase in IRES activity at 3 DIV (Fig. 7A), which reached a value
(0.22) close to that obtained in neuron/astrocyte coculture (0.27), indicating that diffusible factors released from astrocytes stimulate the neuronal FGF-2 IRES activity. This effect is transient; indeed, the ACM was no longer effective at 5 DIV (data not shown).

In order to identify some of these diffusible factors, we investigated the potential involvement of FGF-2 itself, as it is released by astrocytes and favors neuronal survival and development (Walicke et al. 1986; Unsicker et al. 1987; Mattson and Rychlik 1990). Inhibition of its receptor by the antagonist SU5402 (Mohammadi et al. 1997) significantly decreased (about 30\%) the effect of ACM on FGF-2 IRES activity (Fig. 7A). In addition, FGF-2 treatment increased the FLuc/RLuc ratio in a dose-dependent manner (Fig. 7B), and the maximal increase obtained with $10 \mathrm{ng} / \mathrm{mL}$ FGF-2 suggested the involvement of high affinity FGF-2 receptors. This increase was similar to that induced by the ACM treatment (Fig. 7A) or
A

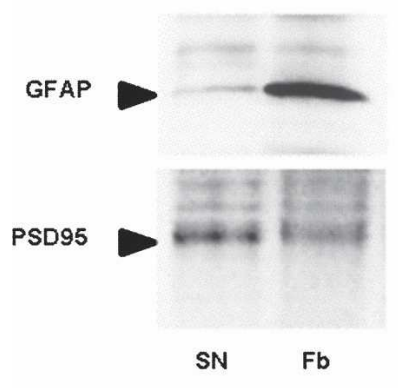

C

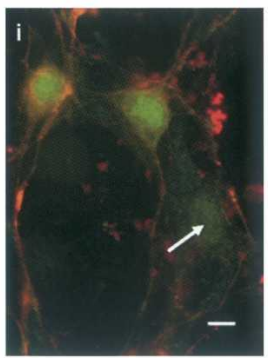

FLuc/ $\beta$-tubulin

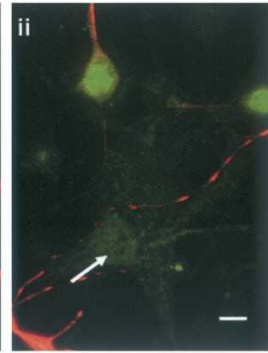

FLuc/MAP2
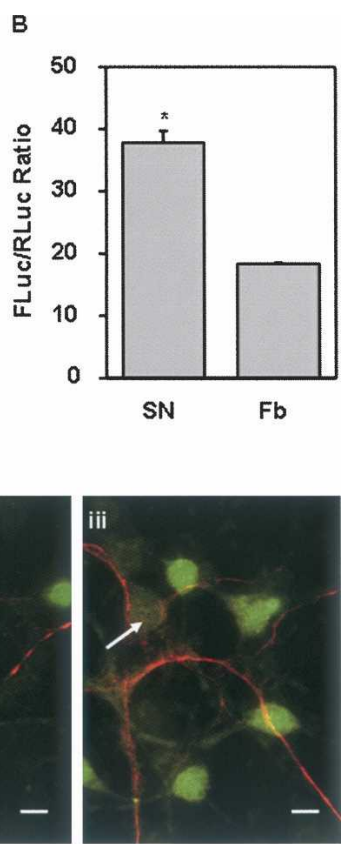

FLuc/GFAP
FIGURE 5. Cellular localization of FGF-2 IRES activity. (A) Western blots were performed on protein extracts $(\mathrm{Fb})$ or a synaptoneurosomal preparation (SN) from forebrains of P6-7 transgenic mice. Immunoblotting was performed with antibodies raised against either the GFAP astrocyte marker or the PSD95 nerve terminal marker, respectively. (B) FGF-2 IRES activity in crude forebrain extracts $(\mathrm{Fb})$ and synaptoneurosomes ( $\mathrm{SN})$ is given as the FLuc/RLuc ratio. Luciferase activities were measured as described in Materials and Methods. Data are expressed as means \pm SEM of duplicate determinations from three separate experiments. $(C)$ Neuronal FLuc localization. Immunofluorescent localization in 10 DIV neuron-enriched cultures of (i) FLuc (green) and the neuronal marker $\beta$-tubulin (red), (ii) FLuc (green) and the neuronal marker MAP2 (red), (iii) FLuc (green) and the glial marker GFAP (red). Fields shown are representative of data obtained from two independent cultures. White arrows indicate typical morphologically characterized astrocytes $(\mathrm{bar}=20 \mu \mathrm{m})$. 
TABLE 3. FGF-2 IRES activity in primary cultures of cortical neurons or astrocytes

\begin{tabular}{lcc}
\hline & \multicolumn{2}{c}{ FLuc/RLuc ratio } \\
\hline Dissociated cells & E16 embryos, & P3-P5 pups, \\
& $0.027 \pm 0.009$ & $14.46 \pm 0.65$ \\
10 DIV cultured cells & Neurons, & Astrocytes, \\
Fold variation & $1.32 \pm 0.29^{\mathrm{a}}$ & $0.050 \pm 0.008^{\mathrm{a}}$ \\
& $\uparrow 49$ & $\downarrow 289$ \\
\hline
\end{tabular}

Cells were dissociated from CTX of RFL12 transgenic mice at E16 or P3-P5, in order to prepare neuron or astrocyte primary cultures, respectively. Cells were grown for 10 DIV. IRES activities were measured in the freshly dissociated cell suspensions and in neurons and astrocytes. Luciferase activities were measured and the FLuc/RLuc ratios were calculated. Values represent the means \pm SEM of triplicate determinations obtained from three (astrocyte) or five (neuron) independent cultures.

${ }^{\mathrm{a}} \mathrm{p}<0.05$.

astrocytes in cocultures. Interestingly, the effect of FGF-2 was not mimicked by another growth factor, brain-derived neurotrophic factor (BDNF), which also promotes neuronal survival (Fig. 7A).

Taken together, these data suggest that FGF-2 is one of the signals released by astrocytes, which contribute to upregulate FGF-2 IRES activity in neurons.

\section{Regulation of FGF-2 IRES activity by electrical activity and glutamate receptors}

Following neuritogenesis, spontaneous electrical activity appears in culture after $1 \mathrm{wk}$ and is involved in neuronal survival, neuronal maturation, and translational activation (Kelleher et al. 2004). Accordingly, we investigated the effect of tetrodotoxin (TTX), a blocker of spontaneous electrical activity on FGF-2 IRES activity. TTX treatment of cortical cocultures from 7 DIV to 10 DIV decreased the FLuc/RLuc ratio by about $40 \%$ (Fig. 8 ).

The blockade of glutamate ionotropic receptors either by D-AP5 (D-2-aminophosphonovalerate), an NMDA ( $N$-methyl-D-aspartate) receptor antagonist or by NBQX (6-nitro-7-sulphamoyl-benzo[f] quinoxaline-2,3-dione), an AMPA ( $R S$ - $\alpha$-amino-3-hydroxy-5-methyl-4-isoxazolepropionate) receptor antagonist, also decreased the FLuc/RLuc ratio (Fig. 8). Interestingly, a combination of these ionotropic receptor antagonists decreased this ratio to the same extent as TTX. Thus, spontaneous excitatory activity partly contributes to the regulation of FGF-2 IRES activity during development.

\section{DISCUSSION}

We report here a specific and stringent spatiotemporal regulation of FGF-2 IRES-dependent translation in the CNS, which takes place into neurons, is dependent upon critical periods of brain development, and is also observed in cell culture during neuronal maturation.
This regulation is specific of the FGF-2 IRES sequence, as other eukaryotic or picornaviral IRESs do not exhibit a similar regulation, and restricted to one tissue, the brain. In addition, cerebral IRES activity is strongly regulated in time and space: during development, levels of IRES activity are very high and peak at the post-natal day P7; in the adult, distribution of IRES activity is heterogeneous within brain areas. Importantly, the integrity of the FGF-2 bicistronic mRNA and the good correlation between Rluc activity and bicistronic mRNA expression clearly demonstrates that the stringent regulation of IRES activity is due to an IRESdriven mechanism of translation, as documented in other in vitro and in vivo studies (Creancier et al. 2000; Doerwald et al. 2003; Martineau et al. 2004; Teshima-Kondo et al. 2004; Bonnal et al. 2005; Gonzalez-Herrera et al. 2006). Furthermore, the changes in IRES activity during neuronal maturation and its modulation by electrical activity as well as by pharmacological agents strongly support the physiological relevance of this regulation.

The neuronal localization of IRES activity is demonstrated by its enrichment in synaptoneurosome preparations, by its high activity in neuronal cultures, and by its very low activity in astrocytes. In addition, FLuc protein is always detected by immunocytochemistry into neurons of transgenic mice, but never into astrocytes. Interestingly, increased $\mathrm{N}$-myc and APAF1 IRES activities were also reported in neuronal precursors and neuroblastoma cell lines (Jopling and Willis 2001; Mitchell et al. 2003).

A wave of strong increase in IRES activity is observed during the first week of post-natal development at a time of intense synapse formation. As this event should be linked to specific neuronal processes, it may be related to neuronal maturation, which occurs during development or neuronal plasticity, which partly recapitulates this process in the adult. Accordingly, the early maturation of the B\&P would explain the early increase of IRES activity at E19 in this structure, whereas the persistent high IRES activity in the adult forebrain and $\mathrm{OB}$ would result from the continous neuronal plasticity described in these brain areas. Interestingly, plasticity in the adult includes translational events (Kelleher et al. 2004) and FGF-2 has been proposed to play a role in this phenomenon (Ishiyama et al. 1991).

The relation between neuronal maturation and FGF-2 IRES-dependent translation is also found in cell culture. The increase of IRES activity measured in neurons correlates with the growth of neuritic processes. In addition, astrocytes that stimulate neuritic outgrowth and participate in synapse formation and stabilization also increase neuronal IRES activity. Finally, we also show that the astrocyte effect is partly due to FGF-2 secretion, which then activates 
A

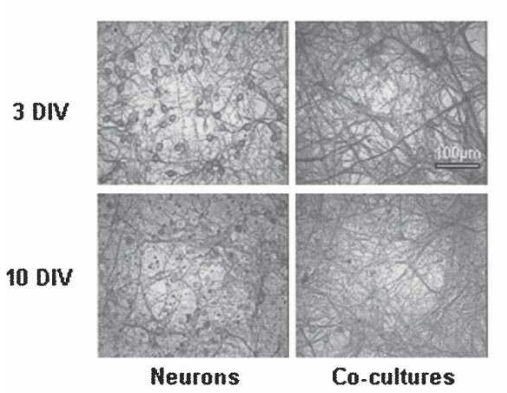

C

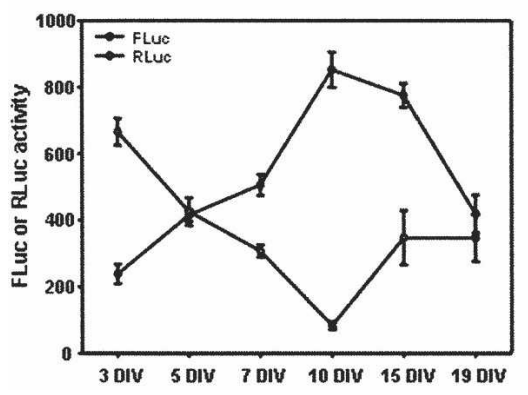

B

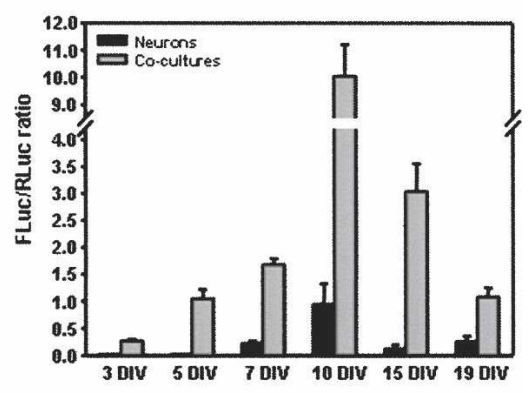

D

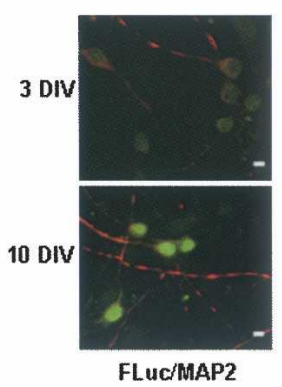

$E$

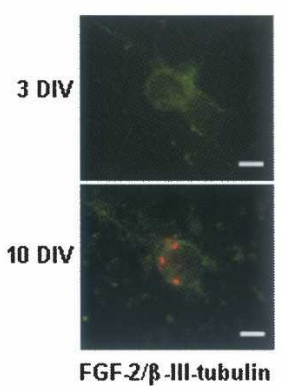

FIGURE 6. Temporal regulation of FGF-2 IRES activity in neuron cultures and neuron/ astrocyte cocultures. Cortical cell cultures were prepared as described in Materials and Methods and grown for the indicated time. (A) Development of neuritic processes. Immunolabeling was performed on cultures at 3 and 10 DIV with anti- $\beta$-tubulin antibody. Field shown are representative of data obtained from two independent cultures (bar $=100$ $\mu \mathrm{m})$. (B) FGF-2 IRES activity during the development of cell cultures. Luciferase activities were measured in neuron-enriched cultures (dark bars) and neuron/astrocyte cocultures (gray bars) from 3 to 19 DIV as described in Materials and Methods. FGF-2 IRES activity is given as the FLuc/RLuc ratio. Data are expressed as means \pm SEM of triplicate determinations from one representative experiment (out of three). (C) Firefly $(\bigcirc)$ and Renilla $(\bigcirc)$ luciferase activities from 3 to 19 DIV. These data correspond to the values of the ratios shown in $B$ for the neuron/astrocyte cocultures. (D) Fluc expression during the development of the neuronenriched cultures. Localization of anti-FLuc (green) and anti-MAP2 (red) immunolabeling in 3 and 10 DIV cultures. Fields shown are representative of data obtained from two independent cell cultures $(\mathrm{bar}=10 \mu \mathrm{m})$. (E) Endogenous FGF-2 expression during the development of neuron-enriched cultures. Localization of anti-FGF-2 (red) and anti- $\beta$-III-tubulin (green) immunolabeling in 3 and 10 DIV cultures. Fields shown are representative of data obtained from two independent cell cultures (bar $=20 \mu \mathrm{m})$.

the neuronal FGF-2 IRES-dependent translation. As FGF-2 has been detected in vivo in a subset of neurons surrounded by astrocytes expressing FGF-2 (Gomez-Pinilla et al. 1994), our data strongly suggest that FGF-2 released by astrocytes stimulates its own synthesis in neighboring neurons through an IRES-dependent mechanism, which in turn provides FGF-2 necessary for neuritic outgrowth and synapse formation.

The changes of IRES activity along neuronal culture are the result of a concomitant but opposite regulation of IRES- and cap-dependent translation and are not linked to variations of bicistronic mRNA expression. This switch in mechanisms, previously described by Dyer et al. (2003), may involve a coordinated regulation of factors specific for each mechanism and/or common factors with opposite effects on the two translational mechanisms. For instance, one of the specific factors could be hnRNP A1, which may be recruited for FGF-2 IRES activity (Bonnal et al. 2005) and is highly expressed in brain, preferentially in neurons (Faura et al. 1995; Kamma et al. 1995). On the other hand, events linked to cap-dependent translational inhibition such as eIF4E and eIF4Ebinding protein (4E-BP) dephosphorylations, eIF2 $\alpha$ phosphorylation, and $4 \mathrm{E}-$ $\mathrm{BP}$ overexpression have all been associated with IRES-mediated translation (Fernandez et al. 2002; Dyer et al. 2003). Whereas such a switch in translational mechanisms in mammalian cells has often been found associated with stress conditions (Fernandez et al. 2002; Holcik and Sonenberg 2005), we show here that it can also exist under physiological conditions, namely, during neuronal maturation.

In developing synapses, NMDAreceptor activation concomitantly inhibits total protein synthesis and stimulates the translation of $\alpha-\mathrm{Ca}^{2+} /$ calmodulindependent kinase II ( $\alpha$-CaMKII) mRNA (Scheetz et al. 2000), which contains an IRES (Pinkstaff et al. 2001). Similarly, electrical activity and glutamate receptors participate in the stimulation of FGF-2 IRES activity during neuronal maturation. Thus, NMDA receptor activation and, more generally, neuronal inputs may be one of the signals triggering IRES-dependent translation of a subset of mRNAs in neurons. Interestingly, several dendritically localized mRNAs contain an IRES in their $5^{\prime}$ UTR (Pinkstaff et al. 2001) and an electrical stimulus is involved in the IRES-dependent translation of the egg-laying hormone in Aplysia (Dyer et al. 2003).

Importantly, FGF-2 IRES activity correlates with endogenous expression of the growth factor in neuronal cultures, and its punctuated cytoplasmic signal corresponds to a localization mainly described in neurons of rat brain (Janet et al. 1987; Gonzalez et al. 1995; Fior-Chadi et al. 2007) and retina (Walsh et al. 2001). However, there is a partial overlap between in vivo IRES activity and the endogenous sites of FGF-2 protein expression (Janet et al. 1987; GomezPinilla et al. 1994; Gonzalez et al. 1995). Many reasons can be invoked, notably the alternative cap-dependent translation of FGF-2, but also a differential regulation occurring at the promoter level or in the $3^{\prime}$ UTR. It is nevertheless 
A

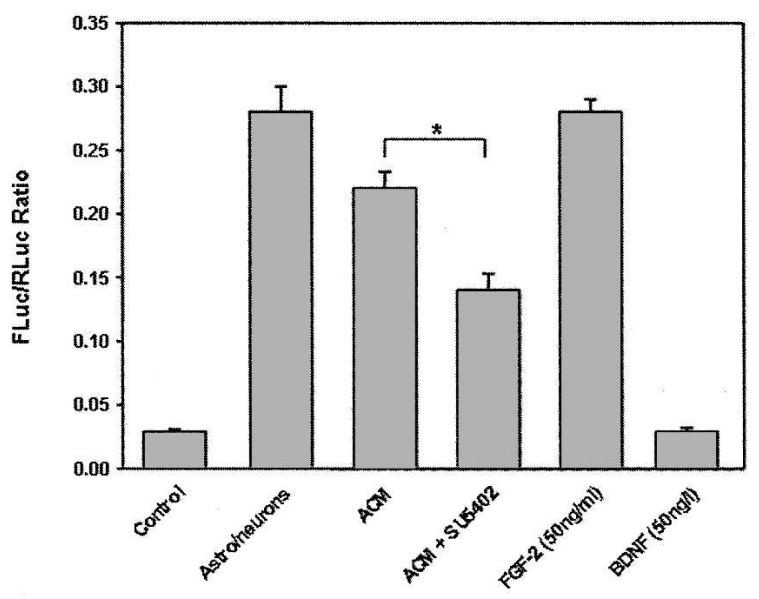

B

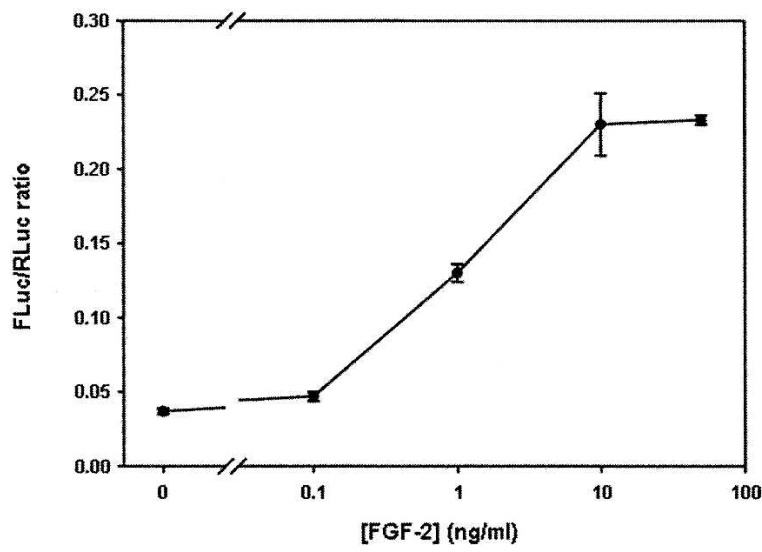

FIGURE 7. Regulation of FGF-2 IRES activity by diffusible factors in 3 DIV neuronal cultures. Neuron-enriched cultures and neuron/ astrocyte cocultures were prepared as described in Materials and Methods. Cells were treated $2 \mathrm{~h}$ after plating with $(A)$ an astrocyteconditioned medium (ACM) either in the presence or the absence of FGF receptor 1 inhibitor SU5402 $(10 \mu \mathrm{M})$, with FGF-2 $(50 \mathrm{ng} / \mathrm{mL})$ or BDNF $(50 \mathrm{ng} / \mathrm{mL})$, or with $(B)$ increasing concentrations of FGF-2. Luciferase activities were measured as described in Materials and Methods. FGF-2 IRES activity is given as a FLuc/RLuc ratio. Data are expressed as means \pm SEM of triplicate determinations obtained in a representative experiment (out of three).

noteworthy that FGF-2 has been clearly detected in regions of high FGF-2 IRES activities, i.e., CTX, STR, and HC (Reuss and von Bohlen und Halbach 2003).

Although there is no doubt about the expression and the role of FGF-2 in brain, the conditions leading to its alternative IRES-dependent mode of translation remain to be clarified. The neuronal inputs, which inhibit capdependent translation while allowing the expression of a subset of proteins, represent one answer. Perhaps, IRESdependent translation of some proteins, such as FGF-2, occurring in specific neurons or even synapses while total protein synthesis is inhibited, is necessary for the formation of the neuronal network and later participates in the plasticity of this neuronal network. FGF-2 also plays a prominent role in post-lesional or post-stress plasticity, a phenomenon that generally involves the reactivation of some developmental mechanisms. Interestingly, Wei et al. (2000) have observed a rapid increase in FGF-2 immunoreactivity following cerebral ischemia, notably into neurons of frontoparietal cortex and striatum, both regions exhibiting a maximal FGF-2 IRES activity. As global protein synthesis is severely inhibited during cerebral ischemia (Althausen et al. 2001), it is tempting to speculate that IRES-dependent translation is turned on to produce FGF-2. Thus, besides its participation in CNS development and plasticity, the IRES-dependent translation of FGF-2 in neurons may also be relevant to brain pathology.

\section{MATERIALS AND METHODS}

\section{Materials}

All experiments were carried out in accordance with the European Communities Council Directive of 24 November 1986 (86/609/ ECC). Versene, antibiotics, and fetal calf serum (FCS) were from Invitrogen and culture media from Eurobio. Monoclonal mouse anti-GFAP (clone G-A-5), anti-PSD95 (clone 7E3-IB8), anti- $\beta$ tubulin (clone TUB2.1), and anti-MAP2 (2a+2b) (clone AP-20) were from Sigma, mouse anti-FGF-2 from UBI, and rabbit anti-FLuc from Europa Bioproducts. Rabbit polyclonal anti- $\beta$-III-tubulin was from Chemicon (AB9324). Secondary antibodies, i.e., alexa fluor 488-conjugated anti-rabbit, Cy3-conjugated anti-mouse, and

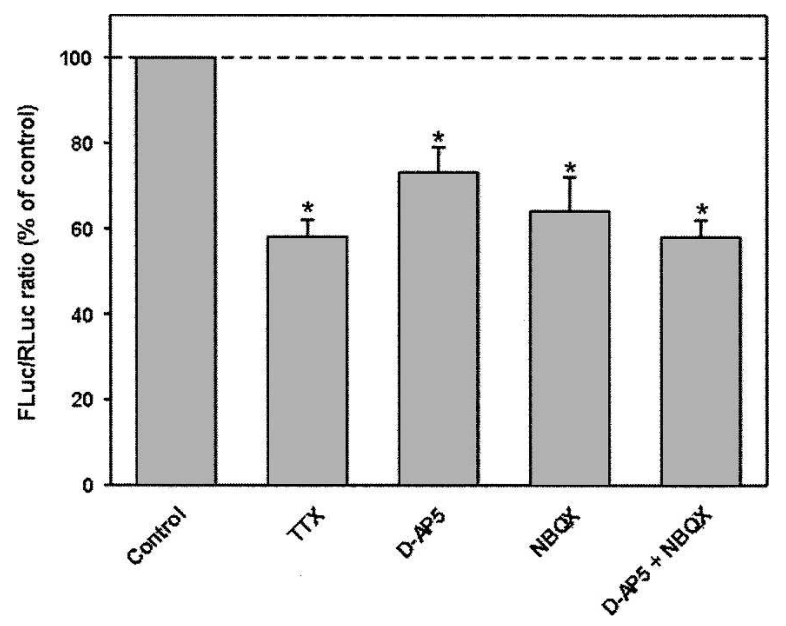

FIGURE 8. Regulation of FGF-2 IRES activity by electrical activity and ionotropic glutamate receptors in 10 DIV neuron/astrocyte cocultures. Cocultures were prepared as described in Materials and Methods. Cells were treated from 7 to 10 DIV with water (control) or TTX $(0.5 \mu \mathrm{M})$ or with glutamate receptor antagonists D-AP5 $(50 \mu \mathrm{M})$ and NBQX $(25 \mu \mathrm{M})$ or a combination of both. Luciferase activities were measured as described in Materials and Methods. FGF2 IRES activity is given as FLuc/RLuc ratio. Data are expressed as percentages of the FLuc/RLuc ratio obtained in untreated cultures. Values represent the means \pm SEM of triplicate determinations obtained in a representative experiment (out of three). 
peroxidase (HRP) conjugated anti-mouse were from Molecular Probes, Jackson Laboratories, and Amersham, respectively. Vectastain $\mathrm{ABC}$ Elite and VIP peroxidase substrate kits were from AbCys. SU5402 and Fluorsave were from Calbiochem, TTX from Alomone Labs, and D-AP5 and NBQX from Tocris. "Dual luciferase" kit and "SV total RNA isolation system" were from Promega.

\section{Transgenic mice}

Transgenic mice carrying the biscistronic constructs CMV-RLucFGF-2 IRES-Fluc, CMV-RLuc-EMCV IRES-Fluc, and CMVRLuc-c-myc IRES-Fluc and their respective mouse line RFL12, RFLD, RELA, and RMYL-28 are described in Creancier et al. (2000) and Creancier et al. (2001). The transgenic mice carrying the biscistronic constructs CMV-RLuc-VEGF IRES A-Fluc and its mouse line A1 are described in Bornes et al. (2007).

\section{Cortical neuron cultures}

The protocol was adapted from Blanc et al. (1999). Cortex from 16-d-old mouse embryos were dissected and incubated for $12 \mathrm{~min}$ in Versene. Cells were mechanically dissociated in a defined neuronal culture medium containing DMEM/HAM-F12 supplemented with $33 \mathrm{mM}$ glucose, $2 \mathrm{mM}$ glutamine, $100 \mathrm{U} / \mathrm{mL}$ penicillin, $100 \mu \mathrm{g} / \mathrm{mL}$ streptomycin, $5 \mathrm{mM}$ HEPES, $13 \mathrm{mM}$ sodium bicarbonate, $50 \mu \mathrm{g} / \mathrm{mL}$ transferrin, $87 \mu \mathrm{M}$ insulin, $1 \mathrm{pM} \beta$-estradiol, $3 \mathrm{nM}$ triiodothyronine, $20 \mathrm{nM}$ progesterone, $46 \mathrm{nM}$ sodium selenite, and $100 \mu \mathrm{M}$ putrescine. Dissociated cells were seeded at a density of 375,000 cells/dish in 24-well plates previously coated with $7.5 \mu \mathrm{g} / \mathrm{mL}$ poly-L-lysine and then with DMEM/HAM-F12 containing 10\% FCS, nd maintained at $37^{\circ} \mathrm{C}$ in $5 \% \mathrm{CO}_{2}$ humidified air. For pharmacological treatment, cells cultured in $500 \mu \mathrm{L}$ neuronal culture medium were incubated with $0.5 \mu \mathrm{L}$ effector. When necessary, treatments were performed with $0.1 \%$ DMSO as the vehicle, a concentration that did not change both luciferase activities. For immunofluorescence, the dissociated cells were seeded on previously coated glass coverslips in eight-well plates at a density of $2 \times 10^{6}$ cells/dish.

\section{Cortical astrocyte cultures}

The protocol was adapted from Plachez et al. (2004). Cortex from post-natal 2- to 5-d-old mice were dissected and incubated for 12 min in Versene. Cells were mechanically dissociated and plated in astrocyte culture medium, at a density of 50,000 cells/dish in 24well plates. Astrocyte culture medium contained DMEM/HAMF12, supplemented with $33 \mathrm{mM}$ glucose, $2 \mathrm{mM}$ glutamine, $100 \mathrm{U} /$ $\mathrm{mL}$ penicillin, $100 \mu \mathrm{g} / \mathrm{mL}$ streptomycin, $5 \mathrm{mM}$ HEPES, $13 \mathrm{mM}$ sodium bicarbonate, and 10\% FCS. Medium was changed every 3 d. Astrocytes reached confluence around 10 DIV.

\section{Neuron/astrocyte cocultures}

Astrocyte cultures from wild-type mice were performed as described above except that cells were seeded on dishes previously coated with $7.5 \mu \mathrm{g} / \mathrm{mL}$ poly-L-lysine. After $7 \mathrm{DIV}$, culture medium was replaced by defined neuronal culture medium. Dissociated cortical cells from E16 transgenic or wild-type embryos were seeded at a density of 375,000 cells/dish on this $70 \%$ confluent astrocyte layer. Cultures were then maintained without any medium change.

\section{Preparation of astrocyte-conditioned medium}

Cultured cortical astrocytes prepared from wild-type mice as described before were grown for 6 DIV. Culture medium was then replaced by defined neuronal culture medium. Twenty-four hours later, medium was collected and referred to as astrocyteconditioned medium (ACM). This ACM was then used to replace the medium of cultured neurons, $2 \mathrm{~h}$ after their plating. In respective controls, medium was replaced by fresh defined neuronal culture medium.

\section{Synaptoneurosome preparation}

Synaptoneurosomes were prepared from forebrains of 6-7-d-old transgenic or wild-type mice according to Recasens et al. (1988).

\section{Measurement of luciferase activities}

Renilla and Firefly luciferase activities were measured on lysates as previously described in Creancier et al. (2000) using a "Dual luciferase" kit. Tissues were directly homogenized in lysis buffer with Dounce potter and centrifuged $\left(10 \mathrm{~min}, 20,000 \mathrm{~g}, 4^{\circ} \mathrm{C}\right)$. Cultured cells were washed once in ice-cold phosphate buffered saline (PBS), lysis buffer was added, and plates were stored at $-80^{\circ} \mathrm{C}$. Cells were then scrapped and lysates were centrifuged. Synaptoneurosomal pellets were directly dispersed in lysis buffer and centrifuged. The supernatants were collected and stored at $-80^{\circ} \mathrm{C}$. Background values of RLuc and FLuc activities measured in extracts from wild-type mice were substracted from the values obtained in the corresponding extract from bicistronic transgenic mice. All statistical analyses were calculated using Fisher's protected least significant difference post hoc test (ANOVA). $P$ values 0.05 were considered significant.

\section{Real-time RT-PCR}

RNA extraction from RFL12 transgenic mouse tissues or cortical neuron cultures were performed with the "SV total RNA isolation system." Reverse transcription (RT) was done on 1 to $3 \mu \mathrm{g}$ total RNA, and real-time PCR was performed with specific probes for RLuc and FLuc as previously described (Teshima-Kondo et al. 2004; Gonzalez-Herrera et al. 2006). Levels of luciferase transcripts were given by the threshold cycle $(\mathrm{Ct})$ value and the data were normalized for the corresponding ribosomal 18S RNA content.

\section{Immunoblotting}

Proteins were extracted by sonication in boiling 2\% SDS. Samples diluted in loading buffer were boiled for $5 \mathrm{~min}$ before loading on a $10 \%$ SDS-PAGE. After electrophoresis, proteins were electrotransferred $\left(2 \mathrm{~mA} / \mathrm{cm}^{2}\right)$ to nitrocellulose membrane using a semidry blotting system. Blots were probed with primary antibodies (1/1000 anti-GFAP or $1 / 2000$ anti-PSD95) and then incubated with HRP-coupled secondary antibody. Bound antibodies were revealed using ECL (Amersham).

\section{Immunocytochemistry}

Single labelings were performed directly on plastic wells as described in Blanc et al. (1999). Cells were fixed for 20 min with $4 \% \mathrm{PF}$ in $0.1 \mathrm{M}$ sodium phosphate buffer and then incubated for $5 \mathrm{~min}$ in $8 \mathrm{mM}$ sodium borohydride in PBS. After washes, cells 
were preincubated for $1 \mathrm{~h}$ in PBS containing 0.2\% BSA (PBSBSA), $10 \%$ horse serum, and $0.1 \%$ Triton. Incubation with anti$\beta$-tubulin antibody $(1 / 200)$ was performed overnight at $4^{\circ} \mathrm{C}$ in PBS-BSA and $1 \%$ horse serum. After two washes in PBS-BSA, cells were incubated in biotinylated secondary antibody from the Vectastain ABC Elite kit and samples were processed as described by the manufacturer. HRP activity was revealed using the "VIP peroxidase substrate" kit.

Double-labelings were performed by immunofluorescence on neurons cultured on glass coverslips. Cultures were fixed as described above. After washes, cells were preincubated for $1 \mathrm{~h}$ in PBS-BSA containing 20\% goat serum and $0.2 \%$ Triton. Cultures were then incubated with a combination of two antibodies, anti- $\beta$ III-tubulin $(1 / 4000)+$ anti-FGF-2 (1/250) or anti-FLuc $(1 / 500)+$ anti-MAP2 $(1 / 500)$ or anti-FLuc $(1 / 500)+$ anti- $\beta$-tubulin $(1 / 200)$ or anti-FLuc $(1 / 500)+$ anti-GFAP $(1 / 500)$ in PBS-BSA containing $2 \%$ goat serum and $0.02 \%$ Triton. After three washes in PBS-BSA, cells were incubated with a combination of goat fluorescent secondary antibodies: Alexa fluor 488-conjugated anti-rabbit and Cy3-conjugated anti-mouse antibodies (1/200 and 1/2000 in PBS-BSA, respectively). After three washes in PBS-BSA, coverslips were mounted with Fluorsave and observed on a Leica DMR microscope.

\section{ACKNOWLEDGMENTS}

We greatly thank Y. Audigier and M. Vignes for help in manuscript preparation. We thank M. Phillipe (IPBS animal facilities), Y. Barreira (IFR31 animal facilities), and JJ Maoret (IFR31 Molecular Biology Plateform) for technical assistance. This work was supported by grants from ARC, AFM, FRM, Canceropole GSO, Conseil Régional Midi-Pyrénées, European Commission FP5 and the French Ministery of Research. I.G.G.H. was supported by successive fellowships from ARC and LNCC (France).

Received August 21, 2007; accepted June 3, 2008.

\section{REFERENCES}

Abe, K., Ishiyama, J., and Saito, H. 1992. Effects of epidermal growth factor and basic fibroblast growth factor on generation of longterm potentiation in the dentate gyrus of fimbria-fornix-lesioned rats. Brain Res. 593: 335-338.

Althausen, S., Mengesdorf, T., Mies, G., Olah, L., Nairn, A.C., Proud, C.G., and Paschen, W. 2001. Changes in the phosphorylation of initiation factor eIF-2 $\alpha$, elongation factor eEF-2 and p70 S6 kinase after transient focal cerebral ischaemia in mice. J. Neurochem. 78: 779-787.

Arnaud, E., Touriol, C., Boutonnet, C., Gensac, M.C., Vagner, S., Prats, H., and Prats, A.C. 1999. A new 34-kilodalton isoform of human fibroblast growth factor 2 is cap dependently synthesized by using a non-AUG start codon and behaves as a survival factor. Mol. Cell. Biol. 19: 505-514.

Baird, S.D., Turcotte, M., Korneluk, R.G., and Holcik, M. 2006. Searching for IRES. RNA 12: 1755-1785.

Blanc, E.M., Jallageas, M., Recasens, M., and Guiramand, J. 1999. Potentiation of glutamatergic agonist-induced inositol phosphate formation by basic fibroblast growth factor is related to developmental features in hippocampal cultures: Neuronal survival and glial cell proliferation. Eur. J. Neurosci. 11: 33773386.
Bonnal, S., Boutonnet, C., Prado-Lourenco, L., and Vagner, S. 2003. IRESdb: The Internal Ribosome Entry Site database. Nucleic Acids Res. 31: 427-428.

Bonnal, S., Pileur, F., Orsini, C., Parker, F., Pujol, F., Prats, A.C., and Vagner, S. 2005. Heterogeneous nuclear ribonucleoprotein A1 is a novel internal ribosome entry site trans-acting factor that modulates alternative initiation of translation of the fibroblast growth factor 2 mRNA. J. Biol. Chem. 280: 4144-4153.

Bornes, S., Prado-Lourenco, L., Bastide, A., Zanibellato, C., Iacovoni, J.S., Lacazette, E., Prats, A.C., Touriol, C., and Prats, H. 2007. Translational induction of VEGF internal ribosome entry site elements during the early response to ischemic stress. Circ. Res. 100: 305-308.

Creancier, L., Morello, D., Mercier, P., and Prats, A.C. 2000. Fibroblast growth factor 2 internal ribosome entry site (IRES) activity ex vivo and in transgenic mice reveals a stringent tissuespecific regulation. J. Cell Biol. 150: 275-281.

Creancier, L., Mercier, P., Prats, A.C., and Morello, D. 2001. c-myc Internal ribosome entry site activity is developmentally controlled and subjected to a strong translational repression in adult transgenic mice. Mol. Cell. Biol. 21: 1833-1840.

Doerwald, L., Onnekink, C., van Genesen, S.T., de Jong, W.W., and Lubsen, N.H. 2003. Translational thermotolerance provided by small heat shock proteins is limited to cap-dependent initiation and inhibited by 2-aminopurine. J. Biol. Chem. 278: 49743-49750.

Dono, R., Texido, G., Dussel, R., Ehmke, H., and Zeller, R. 1998. Impaired cerebral cortex development and blood pressure regulation in FGF-2-deficient mice. EMBO J. 17: 4213-4225.

Dyer, J.R., Michel, S., Lee, W., Castellucci, V.F., Wayne, N.L., and Sossin, W.S. 2003. An activity-dependent switch to cap-independent translation triggered by eIF4E dephosphorylation. Nat. Neurosci. 6: 219-220.

Faura, M., Renau-Piqueras, J., Bachs, O., and Bosser, R. 1995. Differential distribution of heterogeneous nuclear ribonucleoproteins in rat tissues. Biochem. Biophys. Res. Commun. 217: 554-560.

Fernandez, J., Yaman, I., Merrick, W.C., Koromilas, A., Wek, R.C., Sood, R., Hensold, J., and Hatzoglou, M. 2002. Regulation of internal ribosome entry site-mediated translation by eukaryotic initiation factor- $2 \alpha$ phosphorylation and translation of a small upstream open reading frame. J. Biol. Chem. 277: 2050-2058.

Fior-Chadi, D.R., Varella, T.C., Maximino, J.R., and Chadi, G. 2007. Aortic coarctation hypertension induces fibroblast growth factor-2 immunoreactivity in the stimulated nucleus tractus solitarii. J. Mol. Histol. 38: 285-294.

Florkiewicz, R.Z. and Sommer, A. 1989. Human basic fibroblast growth factor gene encodes four polypeptides: Three initiate translation from non-AUG codons. Proc. Natl. Acad. Sci. 86: 3978-3981.

Gomez-Pinilla, F., Lee, J.W., and Cotman, C.W. 1994. Distribution of basic fibroblast growth factor in the developing rat brain. Neuroscience 61: 911-923.

Gonzalez, A.M., Berry, M., Maher, P.A., Logan, A., and Baird, A. 1995. A comprehensive analysis of the distribution of FGF-2 and FGFR1 in the rat brain. Brain Res. 701: 201-226.

Gonzalez-Herrera, I.G., Prado-Lourenco, L., Pileur, F., Conte, C., Morin, A., Cabon, F., Prats, H., Vagner, S., Bayard, F., Audigier, S., et al. 2006. Testosterone regulates FGF-2 expression during testis maturation by an IRES-dependent translational mechanism. FASEB J. 20: 476-478.

Goritz, C., Mauch, D.H., Nagler, K., and Pfrieger, F.W. 2002. Role of glia-derived cholesterol in synaptogenesis: New revelations in the synapse-glia affair. J. Physiol. (Paris) 96: 257-263.

Gremo, F. and Presta, M. 2000. Role of fibroblast growth factor-2 in human brain: A focus on development. Int. J. Dev. Neurosci. 18: 271-279.

Han, B. and Zhang, J.T. 2002. Regulation of gene expression by internal ribosome entry sites or cryptic promoters: The eIF4G story. Mol. Cell. Biol. 22: 7372-7384.

Hertz, L. 1991. Neuronal-astrocytic interactions in brain development, brain function and brain disease. Adv. Exp. Med. Biol. 296: 143-159. 
Holcik, M. and Sonenberg, N. 2005. Translational control in stress and apoptosis. Nat. Rev. Mol. Cell Biol. 6: 318-327.

Holcik, M., Graber, T., Lewis, S.M., Lefebvre, C.A., Lacasse, E., and Baird, S. 2005. Spurious splicing within the XIAP 5' UTR occurs in the Rluc/Fluc but not the Bgal/CAT bicistronic reporter system. RNA 11: 1605-1609.

Ishiyama, J., Saito, H., and Abe, K. 1991. Epidermal growth factor and basic fibroblast growth factor promote the generation of long-term potentiation in the dentate gyrus of anaesthetized rats. Neurosci. Res. 12: 403-411.

Janet, T., Miehe, M., Pettmann, B., Labourdette, G., and Sensenbrenner, M. 1987. Ultrastructural localization of fibroblast growth factor in neurons of rat brain. Neurosci. Lett. 80: 153-157.

Jopling, C.L. and Willis, A.E. 2001. N-myc translation is initiated via an internal ribosome entry segment that displays enhanced activity in neuronal cells. Oncogene 20: 2664-2670.

Kamma, H., Portman, D.S., and Dreyfuss, G. 1995. Cell type-specific expression of hnRNP proteins. Exp. Cell Res. 221: 187-196.

Kelleher 3rd, R.J., Govindarajan, A., Jung, H.Y., Kang, H., and Tonegawa, S. 2004. Translational control by MAPK signaling in long-term synaptic plasticity and memory. Cell 116: 467-479.

Komar, A.A. and Hatzoglou, M. 2005. Internal ribosome entry sites in cellular mRNAs: Mystery of their existence. J. Biol. Chem. 280: 23425-23428.

Korada, S., Zheng, W., Basilico, C., Schwartz, M.L., and Vaccarino, F.M. 2002. Fibroblast growth factor 2 is necessary for the growth of glutamate projection neurons in the anterior neocortex. J. Neurosci. 22: 863-875.

Kozak, M. 2003. Alternative ways to think about mRNA sequences and proteins that appear to promote internal initiation of translation. Gene 318: 1-23.

Lieth, E., Towle, A.C., and Lauder, J.M. 1989. Neuronal-glial interactions: Quantitation of astrocytic influences on development of catecholamine neurons. Neurochem. Res. 14: 979-985.

Lippman, J. and Dunaevsky, A. 2005. Dendritic spine morphogenesis and plasticity. J. Neurobiol. 64: 47-57.

Liu, Z., Dong, Z., Han, B., Yang, Y., Liu, Y., and Zhang, J.T. 2005. Regulation of expression by promoters versus internal ribosome entry site in the $5^{\prime}$-untranslated sequence of the human cyclindependent kinase inhibitor p27kip1. Nucleic Acids Res. 33: 3763-3771.

Macejak, D.G. and Sarnow, P. 1991. Internal initiation of translation mediated by the $5^{\prime}$ leader of a cellular mRNA. Nature 353: 90-94.

Martineau, Y., Le Bec, C., Monbrun, L., Allo, V., Chiu, I.M. Danos, O., Moine, H., Prats, H., and Prats, A.C. 2004. Internal ribosome entry site structural motifs conserved among mammalian fibroblast growth factor 1 alternatively spliced mRNAs. Mol. Cell. Biol. 24: 7622-7635.

Mattson, M.P. and Rychlik, B. 1990. Glia protect hippocampal neurons against excitatory amino acid-induced degeneration: Involvement of fibroblast growth factor. Int. J. Dev. Neurosci. 8: 399-415.

Mitchell, S.A., Spriggs, K.A., Coldwell, M.J., Jackson, R.J., and Willis, A.E. 2003. The Apaf- 1 internal ribosome entry segment attains the correct structural conformation for function via interactions with PTB and unr. Mol. Cell 11: 757-771.

Mohammadi, M., McMahon, G., Sun, L., Tang, C., Hirth, P., Yeh, B.K., Hubbard, S.R., and Schlessinger, J. 1997. Structures of the tyrosine kinase domain of fibroblast growth factor receptor in complex with inhibitors. Science 276: 955-960.

Ortega, S., Ittmann, M., Tsang, S.H., Ehrlich, M., and Basilico, C. 1998. Neuronal defects and delayed wound healing in mice lacking fibroblast growth factor 2. Proc. Natl. Acad. Sci. 95: 5672-5677.

Pelletier, J. and Sonenberg, N. 1988. Internal initiation of translation of eukaryotic mRNA directed by a sequence derived from poliovirus RNA. Nature 334: 320-325.

Pinkstaff, J.K., Chappell, S.A., Mauro, V.P., Edelman, G.M., and Krushel, L.A. 2001. Internal initiation of translation of five dendritically localized neuronal mRNAs. Proc. Natl. Acad. Sci. 98: $2770-2775$.
Plachez, C., Martin, A., Guiramand, J., and Recasens, M. 2004. Astrocytes repress the neuronal expression of GLAST and GLT glutamate transporters in cultured hippocampal neurons from embryonic rats. Neurochem. Int. 45: 1113-1123.

Prats, H., Kaghad, M., Prats, A.C., Klagsbrun, M., Lelias, J.M., Liauzun, P., Chalon, P., Tauber, J.P., Amalric, F., Smith, J.A., et al. 1989. High molecular mass forms of basic fibroblast growth factor are initiated by alternative CUG codons. Proc. Natl. Acad. Sci. 86: 1836-1840.

Qin, X. and Sarnow, P. 2004. Preferential translation of internal ribosome entry site-containing mRNAs during the mitotic cycle in mammalian cells. J. Biol. Chem. 279: 13721-13728.

Recasens, M., Guiramand, J., Nourigat, A., Sassetti, I., and Devilliers, G. 1988. A new quisqualate receptor subtype (sAA[2]) responsible for the glutamate-induced inositol phosphate formation in rat brain synaptoneurosomes. Neurochem. Int. 13: 463-467.

Reuss, B. and von Bohlen und Halbach, O. 2003. Fibroblast growth factors and their receptors in the central nervous system. Cell Tissue Res. 313: 139-157.

Scheetz, A.J., Nairn, A.C., and Constantine-Paton, M. 2000. NMDA receptor-mediated control of protein synthesis at developing synapses. Nat. Neurosci. 3: 211-216.

Sherrill, K.W., Byrd, M.P., Van Eden, M.E., and Lloyd, R.E. 2004. BCL-2 translation is mediated via internal ribosome entry during cell stress. J. Biol. Chem. 279: 29066-29074.

Stoneley, M. and Willis, A.E. 2004. Cellular internal ribosome entry segments: Structures, trans-acting factors and regulation of gene expression. Oncogene 23: 3200-3207.

Teshima-Kondo, S., Kondo, K., Prado-Lourenco, L., GonzalezHerrera, I.G., Rokutan, K., Bayard, F., Arnal, J.F., and Prats, A.C. 2004. Hyperglycemia upregulates translation of the fibroblast growth factor 2 mRNA in mouse aorta via internal ribosome entry site. FASEB J. 18: 1583-1585.

Touriol, C., Bornes, S., Bonnal, S., Audigier, S., Prats, H., Prats, A.C., and Vagner, S. 2003. Generation of protein isoform diversity by alternative initiation of translation at non-AUG codons. Biol. Cell. 95: $169-178$.

Unsicker, K., Reichert-Preibsch, H., Schmidt, R., Pettmann, B., Labourdette, G., and Sensenbrenner, M. 1987. Astroglial and fibroblast growth factors have neurotrophic functions for cultured peripheral and central nervous system neurons. Proc. Natl. Acad. Sci. 84: 5459-5463.

Vaccarino, F.M., Schwartz, M.L., Raballo, R., Rhee, J., and LynCook, R. 1999. Fibroblast growth factor signaling regulates growth and morphogenesis at multiple steps during brain development. Curr. Top. Dev. Biol. 46: 179-200.

Vagner, S., Gensac, M.C., Maret, A., Bayard, F., Amalric, F., Prats, H., and Prats, A.C. 1995. Alternative translation of human fibroblast growth factor 2 mRNA occurs by internal entry of ribosomes. Mol. Cell. Biol. 15: 35-44.

van der Velden, A.W. and Thomas, A.A. 1999. The role of the 5' untranslated region of an mRNA in translation regulation during development. Int. J. Biochem. Cell Biol. 31: 87-106.

Van Eden, M.E., Byrd, M.P., Sherrill, K.W., and Lloyd, R.E. 2004. Demonstrating internal ribosome entry sites in eukaryotic mRNAs using stringent RNA test procedures. RNA 10: 720-730.

Walicke, P., Cowan, W.M., Ueno, N., Baird, A., and Guillemin, R. 1986. Fibroblast growth factor promotes survival of dissociated hippocampal neurons and enhances neurite extension. Proc. Natl. Acad. Sci. 83: 3012-3016.

Walsh, N., Valter, K., and Stone, J. 2001. Cellular and subcellular patterns of expression of bFGF and CNTF in the normal and light stressed adult rat retina. Exp. Eye Res. 72: 495-501.

Wang, Z., Weaver, M., and Magnuson, N.S. 2005. Cryptic promoter activity in the DNA sequence corresponding to the pim-1 5'-UTR. Nucleic Acids Res. 33: 2248-2258.

Wei, O.Y., Huang, Y.L., Da, C.D., and Cheng, J.S. 2000. Alteration of basic fibroblast growth factor expression in rat during cerebral ischemia. Acta Pharmacol. Sin. 21: 296-300. 

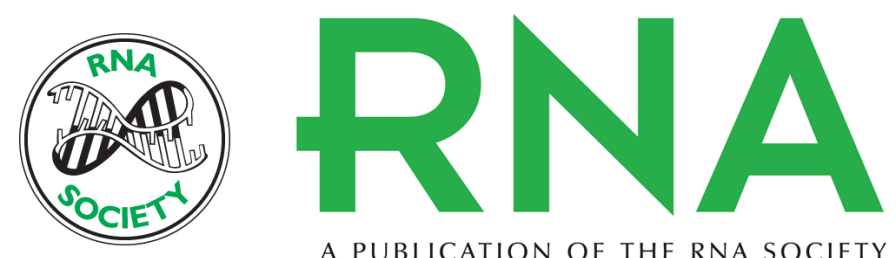

A PUBLICATION OF THE RNA SOCIETY

\section{Potent activation of FGF-2 IRES-dependent mechanism of translation during brain development}

Sylvie Audigier, Janique Guiramand, Leonel Prado-Lourenco, et al.

RNA 2008 14: 1852-1864 originally published online August 1, 2008

Access the most recent version at doi:10.1261/rna.790608

$\begin{array}{ll}\text { References } & \begin{array}{l}\text { This article cites } 64 \text { articles, } 25 \text { of which can be accessed free at: } \\ \text { http://rnajournal.cshlp.org/content/14/9/1852.full.html\#ref-list-1 }\end{array}\end{array}$

License

Email Alerting Receive free email alerts when new articles cite this article - sign up in the box at the Service top right corner of the article or click here. 